\title{
Bio prospecting potentials of Dioscorea species in selected districts of Gedio and Sidama zones of SNNPR, Ethiopia
}

\begin{abstract}
Bio prospecting or biodiversity prospecting is the exploration, extraction and screening of biological diversity and indigenous knowledge for commercially valuable genetic and biochemical resources. Ethiopia is lucky to be gifted with rich biodiversity and traditional knowledge that could pioneer successful for bio-prospecting. Ethiopia holds a rich genetic diversity of tropical root and tuber crops which have tremendous medicinal and industrial potential. However, their bioprospecting potential for Access and Benefit Sharing has not been determined. Therefore, the objective of this study was to assess the bioprospecting potential of Dioscorea Species for Access and Benefit Sharing in selected districts of Gedio and Sidama Zones of SNNPR, Ethiopia. A total of 120 respondents, 10 from each kebeles were selected purposively to the semi structured interview. The results of this study showed that Dioscorea species is the most abundant among root crops in the study areas. It has several traditional medicinal uses such as stomach ache occur during delivery, itch, abscess, ringworm/fungal diseases, brain tumor, hypertension, stomach bloating and kidney infections. Based on the traditional use of Dioscorea species as base line and other related experimental studies, the essential extracts of Dioscorea species used by the local people of the study area might have industrial applications for pharmaceuticals, food and cosmetics industries for Access and Benefit sharing (ABS).
\end{abstract}

Keywords: Discorea species, bio-prospecting, traditional medicine and industries
Volume 5 Issue 3 - 2018

\author{
Amare Seifu, Manaye Misganaw, GirumFaris, \\ Ashenafi Ayenew, Tesfaye Bekele, Nigussie \\ Seboka \\ Ethiopian Biodiversity Institute, Ethiopia
}

Correspondence: Amare Seifu, Ethiopian Biodiversity Institute, Ethiopia,Tel: +251916595709; Email ameseifu21@gmail.com

Received: January 24, 2018 | Published: May 07, 2018
Abbreviations: SNNPR, south nation nationality people regional state; SPSS, statistical package for social science; ABS, access and benefit sharing; FAO, food and agriculture organization; GZFED, gedeo zone finance and economic development; SZFED, sidama zone finance and economic development.

\section{Introduction}

Bio prospecting or biodiversity prospecting is the exploration, extraction and screening of biological diversity and indigenous knowledge for commercially valuable genetic and biochemical resources. It covers a wide range of commercial activities in different industrial sectors including pharmaceuticals, food and beverages, biotechnology, seed, crop protection, horticulture, botanical medicines and cosmetics and personal care. ${ }^{1,2}$ It provides valuable leads for new product development and many companies look for new applications of biological species that have not been studied earlier. ${ }^{1}$ However, its definition varies in scope between countries, with some defining bio prospecting narrowly to include only the search for valuable genetic materials, whereas others encompass the development and application of such materials. Hence, the commercialization aspects of bio prospecting and potential profitability remain the critical bottleneck regarding its legal definition. ${ }^{3}$ Root and tuber crops are the third important group of food crops after cereals and pulses, feeding about one fifth of the world population. ${ }^{4}$ Moreover, these crops have high traditional medicinal and industrial uses. Species of the genus Dioscorea (family Dioscoreaceae) are widely used as botanical dietary supplements. These plants are well known for containing steroidal saponins, mainly belonging to the spirostanol and furostanol classes, and these have been used as chemical marker compounds for quality control of the botanical products..$^{5-7}$

Dioscorea villosa which is one of the Dioscorea species is edible and used for centuries as a medicinal herb for a wide range of ailments. ${ }^{8}$ The original use of Dioscorea villosa was as a source of the raw material used to manufacture contraceptive. It is sometimes suggested as an alternative to hormone replacement therapy. The components of Dioscorea villosa are chemically manufactured into the hormones progesterone or estrogen since the body is unable to use Dioscorea villosa in the same way. Amongst the medicinal yams, Dioscorea villosa is mentioned in English pharmacopoeias. Extracts of Dioscorea villosa also help to women with menopausal and PMS (premenstrual syndrome) symptoms. It is also said to be good for labor pains and the prevention of early miscarriage. Other sources reported that it is good for the nausea that can be experienced during pregnancy. ${ }^{9}$ Dioscorea villosa is a popular herbal remedy for pains associated with rheumatism and arthritis, colic and intestinal cramps, proving itself a reliable antispasmodic and anti-inflammatory. ${ }^{10}$ Of all remedies, it is the most effective in the treatment of bilious colic, as well as being a useful treatment for rheumatis. ${ }^{11}$ In herbal medicine the root is used for intestinal colic (and indigestion), to soothe diverticulitis, relieve dysmenorrhoea, as well as allay uterine and ovarine pain. The most significant use is in the treatment of rheumatoid arthritis to relieve the intense inflammation in the acute phase. It is also used for muscular rheumatism and spasmodic asthma. ${ }^{12}$ Dioscorea species has many traditional medicinal uses in the study areas. From this observation, as a baseline, the essential extracts from Dioscorea species used by the local people of the study area might have an industrial application which is not properly and systematically utilized currently in Ethiopia. Moreover, most of the local community uses this genetic 
resource traditionally. However, less attention is given to the studies of Dioscorea species in Ethiopia and very few investigations have been undertaken since then. Therefore, this research aims at bioprospecting the indigenous knowledge on Dioscorea species for industrial application and identifying potential distribution areas of the species around the study area so as to promote it for access and benefit sharing purposes.

\section{Materials and methods}

\section{Study area}

The study was conducted from 20, November to 20, December 2017, in Sidama and Gedio Administration Zone in a six selected districts, namely, Dilla Zuria, Wonago, Kochere, Bensa, Dara and Aleta Wondo of the Southern Nations, Nationalities, and Peoples' Region (SNNPR). Sidama zone is located in the north eastern part of the region and bounded by Oromia in the North, east and south east, with Gedieo Zone in the south, and Wolayta Zone in the west. Its geographic location lies between $6^{0} 14^{\prime}$ and $7^{\circ} 18^{\prime}$ North latitude and $37^{\circ}$ 92' and 39 ${ }^{\circ} 14^{\prime}$ 'East longitude with an elevation ranges from 1500 and $2500 \mathrm{~m}$ above sea level. ${ }^{13}$ Gedio Zone is located in north eastern part of the region and surrounded by Oromia region in the south, southwest, and Abaya district in the northwest and east directions, and Sidama zone in north direction Figure 1. It is found between $6^{0} .59$ $6^{0} .62$ north, latitude and $38^{0} .40-38^{0} .43$ east longitude and $365 \mathrm{~km}$ to Addis Ababa. ${ }^{14}$

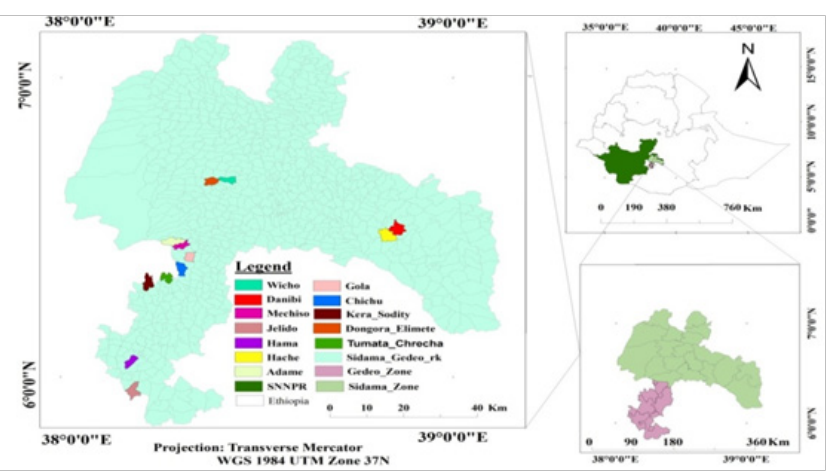

Figure I Administrative map of the study area.

\section{Sampling Design}

The study areas were selected purposely based on the recommendations of zonal agricultural office where Dioscorea species are more grown Zones and districts. Based on this six potential growing districts were selected from Gedio and Sidama zones. Accordingly, Dilla zurya, Wonago, and Kochere districts were from Gedio zone; and Bensa, Dara and Aleta Wondo district were from Sidama zone. Proportionally, the selection of 12 sampling sites (kebeles) two from each district were done.

\section{Data Collection}

Semi-structured interview, group discussion and field observation data collection methods were employed for primary data collection. Secondary source of data was obtained from the agricultural office of the districts, from different books, journals and research article. A total of 120 respondents, 10 from each kebeles were selected purposively to the semi structured interview, and 25 of them were females. Respondents were selected with the help of kebeles extension agents based on knowledge and experience on agricultural activities of Dioscorea species.

\section{Abundance}

Population density of plant species expressed as the number of individuals of plants per unit area, which is calculated as $A=\Sigma \mathrm{W} / \mathrm{N}$, where, $\mathrm{A}=$ abundance; $\mathrm{W}=$ number of individual species/sample; $\mathrm{N}$ $=$ sample size

\section{Data Analysis}

The survey data was analyzed by using Statistical Package for Social Science (SPSS) software version 21. Descriptive statistics such as frequencies, means and percentages were analyzed to determine the bio-prospecting potential of Dioscorea species.

\section{Result and discussion}

\section{Households characteristics}

Concerning to the age of the respondents, a little below half of the heads of the household ( $49.4 \%$ ) had age between $36-50$ years old, while $31.6 \%$ of the heads of the households were aged between 21 and 35 years old, $17.4 \%$ of the heads of the households were aged between 51 and 75 years old and $1.6 \%$ of the heads of the households were aged greater than 75 years old. The age of respondents were between 22 years old (the minimum age) and 82 (maximum age) with the mean age of 41years old. Most of the respondents were males (79.2\%) and only a few of them were females (20.8\%).All the participants were married. As to the educational status of the respondents $10.8 \%$ of the respondents were uneducated, while $2.5 \%$ of the participants had informal education, $69.2 \%$ of them studied primary (First cycle, grades 1-4 and Second cycle, grades 5-8) and 17.5\%of them studied Secondary High School (grades 9-10)education. The educational status of the respondents ranged between uneducated (illiterate) households heads up to Secondary High School. Assessment in the job category of the respondents indicated that all of the respondents were farmers.

\section{Distribution and abundance of Dioscorea species in comparison with other underutilized and neglected root and tuber crops in the study areas}

All respondents agreed that Dioscorea species were commonly grown in the study areas. This might be due to better productivity, suitability of the crop for food, appropriateness of agro ecology, high market demand and better price. As a result Dioscorea species was the most frequent root and tuber crop followed by Colocasia esculenta and Ipome abatatas respectively in the study areas. On the other hand the most abundance underutilized and neglected root and tuber crop was Ipomea batatas followed by Discorea species and Colocasia esculenta respectively. Concerning to the dominance, Ipomea batatas was the most dominance followed by Discorea species and Colocasia esculenta respectively. On the other hand Manihot esculenta was the least abundance, dominance and frequent, this might be due to lack of awareness about the use of the plant in the study area (Table 1) (Figure 2).

\section{The traditional medicinal use of Dioscorea spp in the study areas}

Based on the respondents report, the traditional medicinal use of Dioscorea species were;- stomach ache occur during delivery, 
itch, abscess, ringworm/fungal diseases, brain tumor, hypertension, stomach bloating and kidney infection. The leaves and roots of these plants were predominantly used for traditional medicinal purpose. Most of the respondents noticed the use of Dioscorea species for stomach ache occur during delivery which has been supported with various experimental study. also reported that extracts of Dioscorea villosa help to women with menopausal and premenstrual syndrome symptoms. It is also said to be good for labor pains and the prevention of early miscarriage. Similarly, in the current study majority of the respondents $(60.8 \%)$ aware of the medicinal use of Dioscorea species. Of these, $17.5 \%$ of the respondents replied that root of Dioscorea species were used for the treatment of stomach ache occur during delivery, $15.8 \%$ of them replied root and leaves of Dioscorea species used for the treatment stomachache occur after delivery \& ringworm/ fungal diseases, $20.8 \%$ of them replied leaves of Dioscorea species used for the treatment of ringworm/fungal diseases and brain tumor and $4 \%$ of them replied root for hypertension and insignificant number of the respondents $(2.5 \%)$ replied root and leaves used for the treatment of itch, abscess, stomach bloating and kidney infection while the remaining (39.2\%) respondents were not aware of about the medicinal use of Dioscorea species. Different experimental study also confirmed that Dioscorea species is suggested as an alternative to hormone replacement therapy, ${ }^{6,8}$ reported that Diosgenin an aglycone is a chemical substance found in Dioscorea species which is used commercially in pharmaceutical industry. ${ }^{15,16}$ Also reported that Species of Dioscorea has been also used as sources of saponins for the preparation of steroids in the pharmaceutical industry. Other similar study by ${ }^{17}$ is also confirmed that Dioscorea species is a popular herbal remedy for pains associated with rheumatism and arthritis, colic and intestinal cramps, proving itself a reliable antispasmodic and anti-inflammatory Figure 3. Moreover, many species of Dioscorea have many organic acids and polyphenols present in them and have antioxidant property. Diosgenin an aglycone is a chemical substance found in Dioscorea and are used commercially in pharmaceutical industry. ${ }^{18}$ Apart from diosgenin, dioscorin, dioscin and other alkaloids are also found. Root contains phytosterols, alkaloids, tannin and rich source of starch. Other substance found are aluminum, ascorbic acid, ash, beta-carotene, calcium, chromium, cobalt, iron, magnesium, manganese, niacin, potassium, phosphorus, protein, riboflavin, selenium, silicon, sodium, thiamine, tin, zinc. ${ }^{17}$

Table I Dominance, frequency and abundance of underutilized and neglected root and tuber Crops and their wild relatives in the study area

\begin{tabular}{lllll}
\hline No. & Scientific Name of the Plants & Dominance (\%) & Frequency (\%) & Abundance \\
\hline I & Colocasia esculenta & 5.16 & 91.67 & 497.04 \\
2 & Discorea species & 7.04 & 97.5 & 677.6 \\
3 & Ipomea batatas & 86.7 & 88.33 & 8346.2 \\
4 & Manihot esculenta & 1.05 & 64.17 & 101.16 \\
\hline
\end{tabular}

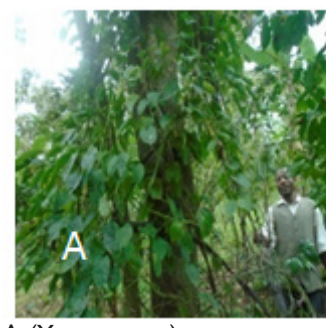

A (Young stage)

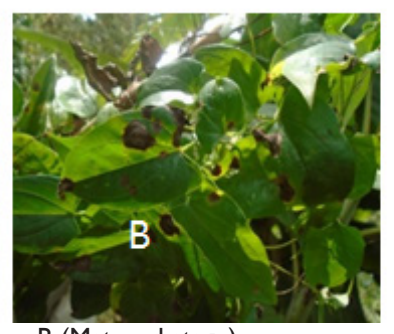

B (Matured stage)

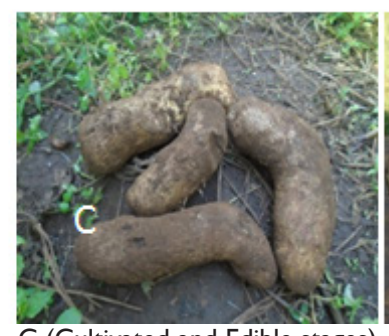

C (Cultivated and Edible stages)

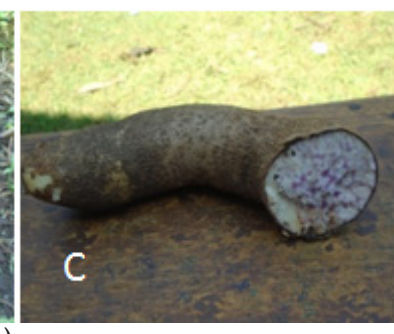

Figure 2 Varieties (farmer cultivars) of Discorea species at different stages of growth

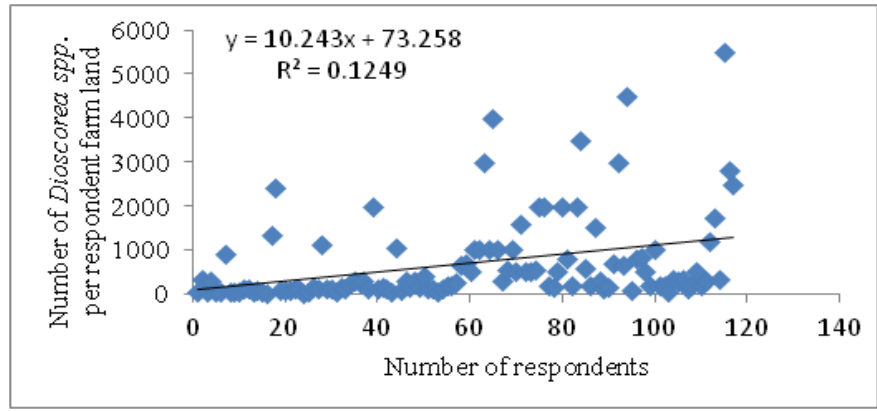

Figure 3 Relationship between numbers of Discorea species in the respondents' farms and sample size.

\section{Conclusion and recommendations}

Dioscorea species and their wild relatives have ample potential for industries Figure 4. Commercializing and bioprospecting this medicinal and food plant, would not only increase the Ethiopia's economic growth, but also contribute to the global stock of pharmaceuticals and food industries. Traditional medicinal plants have lots of potentials, in terms of the provision for the primary health care as well as in the discovery of new drugs, if they are wellmanaged. Dioscorea species are a rich but neglected resource for pharmaceutical and food industry. In, Ethiopia less attention is given to the studies of Dioscorea species. Due to this it needs further studies to bio prospect this species for effective access and benefit sharing. 


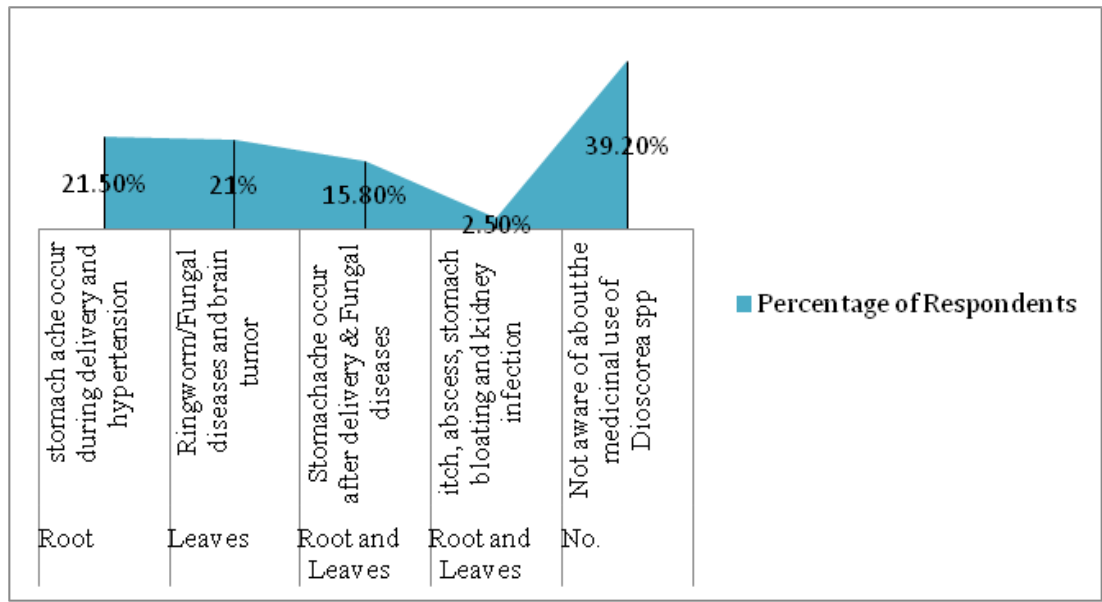

Figure 4 Respondents statements (\%) on the Parts of Dioscorea spp used to treat different diseases.

\section{Acknowledgments}

We gratefully acknowledge Ethiopian Biodiversity Institute for its financial support during the field work. We also acknowledge Sidama and Gedio Agricultural office experts and the respondents for sharing their precious knowledge and experiences.

\section{Conflict of interest}

The author declares that there is no conflict of interest.

\section{References}

1. Afreen S, Abraham BP. Bioprospecting: Promoting and Regulating Access to Genetic Resources and Benefit Sharing. Decision. 2009;36(3):121-158.

2. Kursar TA, Capson TL, Cubilla-Rios L, et al. Linking insights from ecological research with bioprospecting to promote conservation, enhance research capacity, and provide economic uses of biodiversity. In: Carson WP, Schnitzer SA, editors. Tropical Forest Community Ecology. UK: West Sussex, Wiley-Blackwell; 2007. p. 429-441.

3. Harvey AL, Gericke N. Bioprospecting: Creating a value for Biodiversity. In: Pavlinov IY, editor. Research in Biodiversity-Models and Application. UK: In Tech, Science, Technology and Medicine open access publisher; 2011.

4. FAO. The food security through commercialization of Agriculture programme in the caribbean region. Italy: Rome, Food and Agriculture Organization of the United Nations; 2013. p. 1-50.

5. Yoon KD, Chin YW, Yang MH, et al. Application of high-speed Counter current chromatography-evaporative light scattering detection for the separation of seven steroidal saponins from Dioscorea villosa. Phytochem Anal. 2012;23(5):462-468.

6. Afiukwa CA, Ogah O, Okechukwu PCU, et al. Anti-nutritional Characterization of Two Wild Yam Species from Abakaliki, Southeast Nigeria Research. Journal of Pharmaceutical, Biological and Chemical Sciences Nutritional. 2013;4(2):840-848.
7. Ahmed Z, Chishti ZM, Johri RK, et al. Antihyperglycemic and Antidyslipidemic activity of aqueous extract of Dioscoreabulbiferatubers. Diabetologia Croatica. 2009:38-39.

8. Fisher C, Painter G. Materia Medica of Western Herbs for the Southern Hemisphere. New Zealand: Aukland; 1996. 91 p.

9. Krochmal Arnold, Connie. A guide to the Medicinal plants of Appalachia. USA: Quadrangle, the Times Book Co; 1973.

10. Howell P. Medicinal plants of the southern Appalachians. Mountain City, GA: Botano Logos Books; 2006.

11. Crellin JK, Philpott J. A reference guide to medicinal plants. Durham, NC: Duke University Press; 1990.

12. Foster S, Duke JA. Eastern/Central Medicinal Plants. Peterson Field Guides. 1990.

13. Gedeo Zone Finance and Economic Development (GZFED). Zonal population by woredas and city Administrations; zonal annual crop area coverage; 2016.

14. Sidama Zone Finance and Economic Development (SZFED). Distribution of population by woredas, city Administrations and urban-Rural Residence; 2016.

15. Sheikh N, Kumar Y, Misra AK, et al. Phytochemical screening to validate the ethno botanical importance of root tubers of Dioscorea species. Journal of Medicinal Plants Studies. 2013;1(6):62-69.

16. Dutta F, Painter G. Food and medicinal values of certain species of Dioscorea with special reference to Assam. Journal of Pharmacognosy and Phytochemistry. 1996;3(4):15-18.

17. Atsukwei D, Daniel EE, Adams MD, et al. Contraceptive Effect of Ethanolic Extract of Dioscoreavillosa Tuber on Reproductive Hormones of Female Wistar Rats. International Journal of Biochemistry Research \& Review. 2015;5(2):135-144.

18. Bhandari MR, Kawabata J. Organic acid, phenolic content and antioxidan activity of wild yam (Dioscorea spp.) tubers of Nepal. Food chemistry. 2004;88(2):163-168. 